\title{
Theorizing Social Media with Elias Status Displays, Mutual Monitoring, and the Genesis of New Sensibilities*
}

\author{
John D. Boy \\ Leiden University \\ Justus Uitermark \\ University of Amsterdam
}

\begin{abstract}
Making sense of interaction in digital spaces is one of the key challenges for contemporary sociology. Our paper makes a contribution to the sociological theorization of social media. It suggests that the dominant framing of social media in terms derived from communications scholarship, particularly the concept of the public sphere, proves unhelpful when trying to make sense of what people overwhelmingly use social media for in their everyday lives. The networked public sphere prism suggests that unbridled opinion exchange and political debate are what characterize social media and thus define our age. This has been part of the utopian investment in networked forms of communications, and has proven an important aspect in the context of recent protest mobilizations and movements for accountability in which social media played a highly publicized role. However, outside of such normative ideals and exceptional contexts, social media are rarely vehicles for opinion exchange or disruptive movements. Rather, from the perspective of everyday life, social media are more often aligned with order than with disruption, and with the display of status rather than reasoned debate. We propose drawing on the work of Norbert Elias to develop an alternate theorization of social media. Elias' early work on the court society, his analysis of the civilizing process, as well as the larger "figurational" approach to the study of human society he founded, are helpful not just in making sense of the status-seeking behavior of social media users, but also the new needs, desires, sensibilities and practices that emerge at the interface of social media and the spaces of everyday life. From Elias' work, we derive structural pressures as well as new sensibilities that emerge in social spaces ordered by an overarching system of rank. While the court-like sociality of social media tends to reinforce rather than challenge social order, this does not rule out that social media can become aligned with movements for social change. In these cases, however, activists have to actively work against pressures toward conformity, so their successes should be seen as exceptions, not as paradigmatic.
\end{abstract}

*Thanks to Anastasia Kavada, Zoetanya Sujon, Thomas Poell, Chris Bail, David Herbert, Stefan Fisher-Høyrem and many others for comments on previous iterations of this paper. 
For as long as there have been social media, commentators have seen them as political phenomena. Early commentators often pointed to the rise of a "networked public sphere," which influential scholars like Manuel Castells and Yochai Benkler proposed would empower citizens by enabling them to communicate across national and associational boundaries. Citizens could therefore build community directly and without government interference (Benkler 2007; Castells 2009). This assessment was premised on seeing social media as vehicles of political discourse. Their distributed nature, in particular, was believed to mark an important advance over mass media under corporate control, since citizens are no longer beholden to elite gatekeepers.

We are now in a period of backlash against these sorts of utopian hopes. In his Antisocial Media, American media scholar Siva Vaidhyanathan presents a sweeping case against Facebook and its properties, detailing the ways the company's business model and algorithms scramble political discourse (Vaidhyanathan 2018). But even before the current backlash, contributors to the debate added a variety of qualifications to the idea that social media constitute a networked public sphere. In an early contribution on what she called the "virtual sphere," Zizi Papacharissi noted that online debates, much like offline ones, are frequently dominated by elites, while danah boyd noted how homophily tends to lead to the formation of multiple public spheres with varying degrees of division between them (Papacharissi 2002; boyd 2005). Lada Adamic and Natalie Glance showed how people with different political opinions polarize into distinct groups instead of engaging in debate-a pattern also captured through phrases like "echo chambers" or "balkanization" (Adamic and Glance 2005). Kazys Varnelis and Anne Friedberg suggested that the rise of networked spaces may have the paradoxical effect of isolating people from one another rather than connecting them (Varnelis 2008). These authors have a more pessimistic assessment than Benkler and Castells, but they apply the same standard. Even as they temper optimism, the ideal of the networked public sphere still motivates and frames their research. When scholars recognize that networked spaces don't really live up to the public sphere ideal, they conceptualize them as deficient public spheres. The overall idea that online sociality can be meaningfully related to the category of the public sphere is accepted even in the work of those who are most critical of the social and political implications of technological change. Perhaps because the normative model of the public sphere advanced by Jürgen Habermas brackets people's embodied existence-their appearances, their drives and desires-it has been seductive for those attempting to make sense of the new experience of mediated togetherness that digital networks have made possible.

The public sphere prism has helpfully elucidated some specific aspects of social 
media, but it has also perniciously narrowed our view 1 By adopting variations on the concept of the public sphere, analysts have failed to grasp and explain what, we argue, is most essential to social media: the display of status. We do not deny that social media can be harbingers of contestation or deliberation. In fact, that is what attracted us to the analysis of social media in the first place. But we feel that we can only grasp deliberation or contestation on social media once we acknowledge that these functions are not central for most users most of the time. If we recognize that social media is-not exclusively but first and foremost-about display of status, we can pose different sets of questions and grasp what has so far been either ignored altogether or considered as noise. Instead of imagining social media as harbingers of revolution or vehicles of progressive social change, we will be able to recognize the many ways in which social media relate to social order-sometimes aiding those who mount challenges to it, but often facilitating backlash against those who fail to stay in their proper place.

Social media users do not necessarily exchange opinions on matters of general interest. Sometimes they show off their new sneakers, send seasonal greetings, or announce their latest professional successes. For most users, social media are generally not tools for democratic participation, but vehicles to present themselves to proximate and remote others. We need to conceive of online interactions not as a realm apart, but as co-extensive with the work we engage in throughout our everyday lives of presenting ourselves to others and interacting with them. While the public sphere frame may have been warranted in the early days of exploration, we can no longer assume that we are leaving appearances and identities behind when going online. Today our online profiles extend and supplement offline identities and relations. This also means starting our investigations at the interface of online and offline relations rather than privileging either realm. There is a politics to this interface, but that politics cannot be grasped through the Habermasian notions that have encased the debate. Drawing on the work of the German sociologist Norbert

\footnotetext{
${ }^{1}$ We are not alone in our exasperation. As early as 2002, American political philosopher Jodi Dean roundly rejected the public sphere prism on the grounds that the internet's underlying technological infrastructure has been designed to facilitate the pervasive commodification of social relations (Dean 2003, 2002). Alice Marwick views the philosophy and design of social media as an expression of a Californian Ideology that is rooted in the libertarian culture of Silicon Valley yet poses as universal (Marwick 2014). Terri Senft's essay "Hating Habermas" (nothing personal, she assures us) tells the story of how she came to feel increasingly convinced that the category of the public sphere did not help to make sense of the anger, bullying and shaming that besieged her online (Senft 2013). We can add Habermas himself to the list as well. One of the core arguments in The Structural Transformation of the Public Sphere is that tendencies towards the public sphere's collapse are "unmistakable, for while its scope is expanding impressively, its function has become progressively insignificant" (Habermas 1991, p. 4). More recently, he argued that there has been "incredible expansion of media publicity and an unprecedented densification of communication networks" while simultaneously "informalization and dedifferentiation" have eroded the public sphere (Habermas 2006, p. 4).
} 
Elias, we propose an alternative that we think will serve us better in bringing into focus social processes playing out in digital spaces-a key challenge for contemporary sociology.

\section{SOCIAL MEDIA AND STATUS}

Profiles and posts on social media are status displays. Sometimes these updates take the form of photos with captions, sometimes they are only written, but they are inevitably displays of status in the sense that individuals present themselves for appraisal by others. The "social" in "social media" refers to the modalities for appraisal by others: social media platforms are, regardless of their specific format, designed to let others respond to status displays and, crucially, to value them through "likes," "retweets" or other forms of recognition. Social media's defining quality is that they offer a stage for status displays and provide the tools to appraise and rank these status displays.

The work of the Norbert Elias provides us with tools to make sense of social media and status politics. Elias is most famous for his book on the Civilizing Process, which examines changes in manners and sensibilities between 1250 and 1750 . The Civilizing Process exemplifies Elias's sociological approach, which is often referred to as figurational sociology. Figurational sociology analyzes how social relations change and how, in parallel, people's feelings and sensibilities change. In a word, it is about how people are connected and composed (see Swaan 2001). The figurational approach is productive for understanding networked and media-saturated societies as it helps to situate psychic states at the individual level (our desires, anxieties, and sensibilities) within broader changes in the structure and nature of interdependencies. It also provides a remedy to dualistic perspectives that regard the online as a realm apart from "real life." Another added benefit is that Elias is deeply committed to purging sociological analysis of "wish-images." The public sphere is such a wish-image. Instead of idealizing social media as a public sphere or criticizing social media for its democratic deficiencies, a figurational analysis wants to understand what sorts of relations form through social media and how people's experiences and sensibilities are constituted.

Elias invites us to situate social media in a long-term historical perspective. To take that long-term perspective to the extreme, we could say that the prehistory of social media started around seventy thousand years ago when homo sapiens evolved a language that enabled our species to communicate in great and complex detail. Historians and evolutionary biologists suggest that homo sapiens' superior language capacity enabled it to outcompete its close relatives-including apes and Neanderthals-by allowing cooperation on a much larger scale. Their sophisticated 
language allowed humans to recognize and develop group symbols. We came to believe and organize in collectives far greater than those predicated on kin relations and face-to-face interactions alone (Elias 1991b). Gossip networks sustain such collectives as they help people to know who to trust and who to shun (Harari 2015). At this point that the management of reputation becomes vital for individuals and collectives. When people become part of dense and extensive networks, Elias argued, they are compelled to consider how their actions will appear to others with whom they are vicariously connected. The Civilizing Process shows how people in Europe were increasingly dependent on each other and therefore had to take one another into account. They feared nature and violence less but experienced greater anxiety of losing face. Social survival increasingly revolved around cultivating manners. As they became embroiled in extensive, dense, and differentiated chains of relations, people gradually developed the habit of eating with utensils, having sex out of sight of family members, and refraining from spitting on the floor (Elias 1994). Viewed in this long-term perspective, social media represent one further step in the long and checkered development of the extension and densification of chains of social relations. Social media link people together in networks where reputation is centrally at stake.

Over time, the vehicles for expression status have transformed-from paintings to photographs to social media posts. In European court society, the oil painting was one important measure of status. As John Berger (1972) noted, the vast majority of oil paintings are not great works of art. Although some sell for record prices to this day, those are the rare exceptions in an otherwise unexceptional genre. Oil paintings were produced, from the sixteenth century onwards, to display the status of the nobles and merchants who had commissioned the paintings. The images typically convey the position of the people in the picture through props and setting: a globe to signal colonial enterprises, fur or gold to express wealth, bucolic landscapes to signify land ownership, and so on. Like photographs taken with portable camerasor indeed social media posts-oil paintings tend to be repetitive. Its subjects appear in the same poses and in the same style. The reason is that the oil painting was not so much a work of art as a proof of status. As the portable photo camera became a household item, taking pictures became an important ritual for all social strata. Just as oil paintings performed specific functions, so do photographs. In their study of photography, French sociologist Pierre Bourdieu and his team show that what people picture and how they circulate the images simultaneously reflects and defines their social position. Like oil paintings, photographs are repetitive as they express a "system of schemes of perception, thought and appreciation common to a whole group" (Bourdieu et al. 1990, p. 6). Pictures are taken during important occasions like weddings or graduations when people congregate to reaffirm their commitment to those being celebrated (the newlyweds, the graduate) and to the institu- 
tions. Bourdieu and his colleagues note that the intensity of photos fluctuates with intensity of family life; pictures are taken when ties are made or remade-think of babies, birthdays and banquets.

Social media and mobile technologies have further increased the number of pictures and accelerated their diffusion. Visual records are now instant and ongoing. Images and videos posted to Instagram, Facebook or Snapchat often register and celebrate social bonds using standardized poses and frames. However, we do see some shifts and variations. Although selfies constitute only a small proportion of social media posts, this style of self-portraiture appears to be much more common now than it was in the past. This might explain why commentators feel that they have to comment on the genre-it represents a shift in what Elias referred to as the "We-I balance," with the individual instead of the group being solemnized (Elias 1991a). While the group dynamics vary, the function of photography to register, affirm and celebrate social bonds is unchanged. That explains why we are able to observe striking regularities in the choice of subjects, genres, and compositions from the Kodak era to the iPhone era.

\section{THE STRUCTURAL PRESSURES OF SOCIAL MEDIA}

Norbert Elias's work in general, and his Court Society in particular, presents a model of how to study simultaneous changes in relations in sensibilities (Elias 1983). As such, it provides conceptual building blocks for our efforts to build alternate mental models for understanding social media. Initially written in the 1930s, Court Society discusses the efforts by members of the French nobility to affirm and promote its status in the court of Louis XIV and his successors. Elias tries to understand the specific type of politics undergirding the exuberant displays of status of the French nobility of the late seventeenth century. Courtiers were engrossed in displays of status and engaged in intense predation. While status displays reflected formal status to some degree (a higher-ranked noble had more resources to invest in attire and could claim a more prominent seat at the banquet), aspiring elites were able to improve their position through diplomatic gossip and the staging of impressive performances of grandeur. For contemporary observers, Elias noted, it is tempting to project currently dominant values like sobriety and thrift on the French court and explain its exuberant displays as mere decadence 1 Instead of merely denouncing exuberant status displays, Elias's goal is to uncover the structural pressures entic-

\footnotetext{
${ }^{2}$ Although The Structural Transformation of the Public Sphere has been read mostly as an attempt to formulate a normative model of the public sphere, it contains a sophisticated analysis of the symbolic economy of the court that is very much in line with Elias. For instance, Habermas also calls attention to "the stress of the grand festivities; these served not so much the pleasure of the participants as the demonstration of grandeur, that is, the grandeur of the hosts and guests" (Habermas 1991, p. 10).
} 
ing people to act the way they did. Could we, analogously, identify the structural pressures exercised through social media? We think we can.

There are important differences between platforms, but there are also structural pressures that operate across social media platforms and affect all users to smaller or greater degrees. To fully grasp what social media are and do, we have to grasp what is common to them before attending to the important variations within and between social media platforms. First, social media extend and facilitate $m u-$ tual monitoring. Through social media, people expose parts of their lives to others. Sometimes their audiences are unknown lurkers, sometimes they are close friends, but social media have mainly intensified what Granovetter refers to as "weak ties" (Granovetter 1973) People are now more intensely and directly connected to distant others. While Granovetter, and many after him, consider weak ties as conduits for information (about jobs, for instance), such ties also are vehicles of social influence and social pressure. Elias argued that the extension and differentiation of interdependencies "requires and instills greater restraint in the individual, more exact control of his or her affects and conduct, it demands a stricter regulation of drives" (Elias 1994, p. 429). Social media are the carriers of these interdependencies as they bind people together-they bring people into view and in dependence of one another. Social media, in this reading, do not effectuate a disruption, but represent one further step in bringing people closer together, for better or worse.

Second, social media collapse the private-public division. Social media enable and encourage their users to exhibit public displays of their private selves. The publicprivate division, which scholars like Hannah Arendt and Michel Foucault identified as fundamental to bourgeois society and its public sphere, is blurred or absent (Arendt 1958; Foucault 1979). Private selves are not bracketed (as the public sphere paradigm would suggest) but become the instruments and stakes in the competition for status.

Third, social media represent stratified systems of rank. While they compel users to exhibit individuality, at the same time they work to standardize individual expressions by imposing metrics, including numbers of friends, followers, or retweets. Such metrics rank users into an overarching hierarchy. Although clearly there are different subdomains or fields within social media, it is nevertheless possible to instantly rank social media users according to basic metrics and to assess their position within social networks. As several authors have noted, the competitive and evaluative logic of the once-popular website Hot or Not lives on in social media platforms (Losse 2012; Reagle 2015; Kotsko 2017). As users, we're all part of a system of judgement. The use of social media analytics to calculate a "social credit score," as has been proposed in China, is simply the consummation of this logic (Persson, Vlaskamp, and Obbema 2015).

Although they vary in intensity and nature between different platforms, these 
structural forces impinge on all social media users. Individuals may try to negotiate, deny, or disrupt these forces, but they cannot altogether escape them. Even deleting social media accounts and going offline provides no sure escape from symbolic hierarchies reflected and shaped by social media. Our "shadow profiles" exist not only in the databases of social media platforms, but also manifest in interpersonal offline encounters, where the fact of not being on Facebook frequently becomes a source, not only of disbelief, but of distrust as well. Some employers reportedly pass over applicants that lack a Facebook profile, and columnists have advised women to pass on dating men without an active presence. Increasingly, escaping social media is only possible by foregoing social relations. These structural forces tend to push in a direction that elicits specific dispositions and sensibilities.

\section{SOCIAL MEDIA DISPOSITIONS}

Let us first consider the dispositions. When we look through the lens of figurational sociology, we do not seek an inclination among social media users to engage in debate premised on communicative rationality. Instead, we foreground their disposition toward decorous status displays. Social media users tend to post images that confirm or boost their status. They exhibit their talent through still life photographs, showcase their personas through selfies, celebrate their social ties with group pictures, and so on. What Erving Goffman said of personal collections of photos is true for many, and likely most, social media posts:

Thus it is in modern times-and as the modern contribution to ceremonial life-that whenever there is a wedding, an investiture, a birthday party, a graduation exercise, an extended voyage begun or terminated, a picnic, a shop opening, a vacation, or even a visit, snapshots may well be taken, developed, and the prints kept easy to hand. Something like self-worship can thus be accomplished. The individual is able to catch himself at a moment when-for him-he is in ideal surroundings, in association with socially desirable others, garbed in a self-enhancing way (which for white-collar men may mean the rough and manly wear of fishermen, hunters, wranglers, or machinists), poised for a promising take-off, terminating to an important engagement, and with a socially euphoric look on his face. A moment when what is visible about him attests to social matters about which he is proud. A moment, in short, when he is in social bloom, ready, therefore, to accept his appearance as a typification of himself. (Goffman 1979, p. 10) 
A casual look at Facebook or Instagram suggests things have remained the same since the time of Goffman's writing, at least as far as the occasions and motivations are concerned. The snapshots "kept easy to hand" have now become scrollable grids of images, and they are shared in much higher numbers at much greater speed. The number of pictures taken each year has increased astronomically from an estimated one billion in 1930, to 25 billion in 1980, to 380 billion in 2012, and a trillion in 2014 (Mirzoeff 2015, p. 6). As devices to record, view, and share snapshots diffuse, people become ever more tightly integrated into a symbolic universe of status displays. As in the court society studied by Elias, acquiring a position requires not just attaining wealth or power, but clearly putting it in evidence in the field of vision.3 Although there are parallels with Thorstein Veblen's thesis on conspicuous consumption, Elias's analysis differs in that it shows how wider chains of social interdependence compel courtiers to play according to the rules of court rationality (Veblen 1934). Their predatory and flashy behavior is not the outgrowth of an "instinct," as it is in Veblen's Theory of the Leisure Class, nor is it properly understood as a manifestation of a culture of decadence. Elias helps to explain why some peopleespecially those at the very center of the symbolic universe-exhibit their status through impressive and forever changing attires and poses.

The logical correlate of displays of status is predation. Most social media users spend much more time viewing their feeds than actively posting. They show an interest in people they care about or news that matters to them. Such interestregardless of its content or subject-tends to be normatively inflected and drawn to instances of transgression. Social media users do not only prey on signs of status decline but also, more positively, search for beauty, wit or inspiration. But what are the meaningful markers of status? What are adequate displays? Finding this out requires monitoring both those with higher status as well as those who are more proximate. Superiors model what one aspires to, though their displays cannot simply be copied by those further down the pecking order without their appearing laughable. Socially more proximate individuals model displays that are adequate to one's own rank, but they, too, cannot simply be copied, because to do so would mean not rising in the esteem of others but merely maintaining one's place. For that reason, those who aspire to achieve recognition-courtiers under Louis XIV or very active social media users today-are engaged in an arms race of stylistic dis-

\footnotetext{
${ }^{3}$ Habermas also recognized that the public-private division is peculiar to the bourgeois public sphere. Like Elias, he extensively discusses the layout of houses and palaces to gauge the architectural inscription of the division or the lack thereof: "[B]eginning with Versailles, the royal bedroom develops into the palace's second center. If one finds here the bed set up like a stage, placed on a platform, a throne for lying down, separated by a barrier from the area for the spectator, this is so because in fact this room is the scene of the daily ceremonies of lever and coucher, where what is most intimate is raised to public importance" (Richard Alewyn, as quoted in Habermas 1991, p. 10).
} 
tinction. Both audiences and stars are incessantly exchanging information on each other's character and status. A social media network is in essence a gossip network where people not only talk about each other but also volunteer information about themselves.

Status has been the key stake in these gossip networks throughout history, but its determinants have changed. There has been an ongoing process of social integration that has blurred categorical status differentials. Women, workers, the young, ethnic minorities, and sexual minorities have not achieved full equality but they no longer have to defer to more established groups to the extent they used to (Wouters 2007). These shifts in the balance of power are indexed by a shift in language. The imperative to "check your privilege" reflects the ongoing challenges against inherited status superiority, just as the backlash against this language illustrates that this battle is far from over. Nevertheless, there has been a longterm trend away from categorical identities that are ascribed at birth and sustained through formal rituals towards personal identities sustained through informal rituals (Collins 2004). Although social differences-along gender, racial or class lines, for instance-continue to be crucial determinants of status differences (Ridgeway 1997; Piketty 2014), status has increasingly come to be seen as reflective of a uniquely individual character, not as derivate of membership to particular groups. Status is being experienced and pursued as a personal project. Attaining and displaying status therefore places reflexive demands on individuals (Giddens 1991).

To successfully navigate social media, users have to master what psychologists refer to as self-presentation and self-disclosure: they need to diplomatically present aspects of their identity and disclose intimate information (Valkenburg and Piotrowski 2017). When they succeed, users receive positive feedback and come to be recognized for who they want to be and what they want to show. Since users decide what and when they share, they can emphasize those parts of their lives they feel most confident about. Recording moments can by itself heighten a sense of excitement and elatedness, and it appears that the vast majority of feedback on social media is positive (Diehl, Zauberman, and Barasch 2016). Not only upbeat posts receive likes and recognition; it has also been found that Instagram and Facebook users who report feeling depressed receive messages of support and consolation (Zhang 2017). Even in the absence of such positive feedback, the very act of building on online persona can be empowering and enchanting. Research among Dutch teenagers has found that managing an online profile boosts self-esteem (Valkenburg and Piotrowski 2017, p. 229). Notwithstanding these findings about the energizing effect social media can have, users are likely to experience a friction between what they feel on the inside and what they show on the outside. What is true for holiday pictures featuring people in the thrall of the moment is also true for heartfelt disclosures of depression: they are not only put on display but also appraised 
(or ignored altogether, which is also a form of evaluation). Young people, in particular, are keenly aware of the ways their online personas and connections define their place in the social world (Milner, Jr. 2016, pp. 230-244).

\section{ANXIETIES AND DESIRES}

Social media users face a dilemma: either selectively represent oneself to maximize recognition (and experience a contradiction between public display and private self) or to more fully represent oneself (and risk ridicule and criticism). The flipside of ample opportunities for self-presentation and self-disclosure is that there is a tension between the carefully curated and crafted posts and everyday experience. This tension did not originate from social media but has been endemic to social life for as long as people sustained extensive communication networks and has been central to sociological theorizing. The imperative to manage impressions is, inter alia, a central theme in Erving Goffman's celebrated work, and for British sociologist Anthony Giddens the reflexive constitution of the self is the key challenge of modernity (Goffman 1959, 1986; Giddens 1991). The idea that increasingly extensive and dense networks confront people with stringent and contradictory demands has been key to Elias's work. He considered it the sociologist's mission to elucidate the broader sets of relations that are at the root of individually experienced anxieties and desires. Seen in this light, social media do not represent a "revolution" in communication but one further step in a long-term process of tightening interconnections that compel individuals to reflect on their own biographies and identities. However, social media arguably amplify and exemplify this predicament by requiring users to think about how they want to present themselves while confronting them with an endless stream of stylized self-images crafted by others.

People stress out about what to post, and they stress out about what they see. Social media users report in surveys that they experience decreased well-being as the expectations of others weigh down on them. Heavy users of social media-those who spend more than two hours on social networking sites-are more likely to report symptoms of anxiety and depression (RSPH 2017). While some people may experience acute stress, others navigate contradictory demands by relativizing, moving elsewhere, or focusing on the positives. But whatever tactic they pursue, they have to find a precarious balance between their anxieties about evoking disapproval and their desire for recognition as well as their dependence on others for confirmation and their commitment to what they feel is their true self. These dilemmas are arguably characteristic of modernity at large, but today social media serves to augment the challenge of self-presentation.

Let us consider the story of David as an illustration of how social media is im- 
plicated in social relations and sensibilities. David is a journalist in his early fifties. He says that he "of course" has an Instagram account-"I have two teenage daughters." He takes comfort in seeing pictures of his daughters partying at clubs as he learned to worry when they don't post pictures on social media. As we go over the few posts in David's Instagram timeline, we especially pushed him to say more about a picture featuring him and his eighteen-year-old daughter Doreen posing in the kitchen. It looked neat. They must have made an effort to stage the picture and choose a filter. But David insisted that he could not recount how the picture came about: "You have to understand, they take pictures all the time. Our days are filled with posing and looking at pictures." So we did not learn much about the story of the kitchen photo. However, he could say one thing: that picture would never have been posted in his timeline without his daughter's explicit permission. "Every picture is screened!" He once posted a picture of his daughter on Facebook without asking her permission. "She was texting me within a minute. No, no! She actually called me. She called me! That hadn't happened in a long time. She thought that the picture showed a pimple. 'Take that picture down immediately!' "

Impression management took on a heightened significance after David and his wife got divorced. Following the divorce, David observed a change in his own social media use. "When I was an established family man, I posted pictures and shared happily." And now? "Now I'm ashamed." His own relations and those of his wife have become entangled on social media, so any picture he posts is seen by her and her relatives. As a result, he doesn't post anymore. His situation became even more delicate when he and ex-wife started dating again. The divorce and the precarious make-up deeply disturbed his daughters. He described them as "street wise." "I don't know how girls from the gymnasium have an argument, but when my daughter and her cousin get into a fight they throw the worst possible insults at each other." Arguments escalate rapidly, with insults aiming at complete denigration. Those insults are now hurled at David and his ex. His oldest daughter is furious at her parents who, she says, "are behaving like teenagers." She is embarrassed to the bone. "It hurts my eyes; I can't watch this." Arguments also turn physical. His daughter throws things at him and her mother, and she spits at them. They are having these fights all the time, they are taking pictures all time, so the question arose: do the pictures show the fights? Do the fights move to social media? David hesitated, then answered, "Initially we feared that she might take the fight to Facebook. But she hasn't." So, none of these family feuds find their way to social media in any way? "No." The pictures remain happy and glamorous.

What to make of these observations? None of them make sense from the perspective of the public sphere-we do not see anything like rational deliberation on issues of public interest. Another reading, along the lines of Christopher Lasch's diagnosis in The Culture of Narcissism, would consider the protagonists in this story 
as self-involved in their attempts to craft a glorified version of their lives (Lasch 1979). Upon closer inspection, however, David and his daughters do not resemble Narcissus in any way. Instead of falling in love with their own self-image, they see themselves through the eyes of others. Their self-monitoring is a means of keeping their imperfections, of which they are keenly aware, from surfacing. Yet another take would be to consider social media users "shameless" (boyd 2006), but we see the opposite. Doreen scans pictures for pimples and is deeply embarrassed by her parents; David feels ashamed and moves his conversation outside the public eye. The divergence between offline and online is striking. "Keeping up appearances" is a rule that all the people in the story live by. They have their fights but they do not take them to social media. The interview also hints to the reasons: there are many onlookers on social media and they come from different circles. Considering that they want to avoid shame and embarrassment, they have much to lose by exposing their conflicts. Whether they happily agree to that by admiring the rich and beautiful, or feel uneasy navigating social media platforms, they all know that social media users are putting on a show that is based on a real story but that isn't the real story. This is not narcissism, but internalized external pressure. We can understand the protagonists, their actions, and their feelings, by considering how they navigate the contradictory demands that exist within their networks as well as in themselves.

\section{SOCIAL MEDIA AND SOCIAL CHANGE}

Social media are frequently imagined as vectors of transformation and disruption, concealing the continuities and conservative schemas that are reproduced by these platforms. In opposition to commentators who view social media as game-changing, disruptive or revolutionary, we argue that they tend to reproduce and stabilize existing norms and hierarchies. The extension and densification of networks facilitated through social media generate social pressures to conform. Social media make easier to find out what your position in the social order is and how you are supposed to behave. Social media also make it easier to spot and shame people who stand out.

Occasionally, we get a glimpse of these pressures when prominent users reveal what goes on behind the facade that is their timelines. Essena O'Neill is a comparatively well-known and radical example. 1 After collecting over half a million of followers on Instagram and earning a sizeable income through product placements, she snapped out of it. She wrote that "social media is not real life," changed the captions of her posts to reveal the dreaded work going into composing seductive posts, and recorded a video message in which she breaks down in tears as she talks

\footnotetext{
${ }^{4}$ See the media accounts linked from her Wikipedia entry at https://en.wikipedia.org/wiki/Essena_0\%27Neill.
} 
about getting caught up in world of deceit. The video went viral and made headlines around the world. Although O'Neill initially received praise, the backlash was intense. As she set up a website and requested donations to fund a book project, O'Neill's critics, including former friends, accused her of self-promotion. Her tearful epiphany, the suggested, was just an elaborate hoax. O'Neill lamented how social media induce people into putting on a show, but found herself accused of fabricating a new online persona. She unwittingly illustrated the paradox that revelations on the treachery of social media are considered treacherous as well-it is logically impossible to really believe someone on social media who tells you to distrust everything on social media. Faithfully adhering to the norms by trying to look your best and rejoicing in the attention can, ironically, look and feel more "real" than having a nervous breakdown and crying your heart out. When she was breaking down and admitted she had been living a lie, Essena O'Neill was considered, in her own words, "a genius manipulator" and a "brilliant actor". As long as she had been a "brilliant actor," she had not been called out as one. The accusations and death threats directed at O'Neill suggest that she was considered a traitor and a hypocrite. Playing along is not merely self-serving but is a tribute to the status hierarchy in which others have invested so much. Speaking out devalues and destroys the symbolic universe that has been created out of the efforts of so many users to produce pleasing images and spotless streams.

The example of O'Neill illustrates just how difficult it is to upset social hierarchies through social media. We think that the affirmation of social order is the rule, not the exception. Since we stress that social media users predominantly showcase that they conform to, or exceed, expectations, how do we account for the numerous debates raging on social media? Does our framework apply here, too? We argue that it does. In our reading, discursive contention does not signal communicative exchange so much as the embodied politics of status displays. What we call a discussion is usually a series of position-takings that are more meant to express identity and commitment than to exchange arguments, which explains why people so rarely change their views (Kolbert 2017). Neuroscientists have found that our Insular cortex and Amygdala are activated when our cherished beliefs are questioned, suggesting we may be deep-wired to protect our ingrained ideas in response to attacks (Kaplan, Gimbel, and Harris 2016). This is especially important when we want to appreciate why people can get so worked up about discussions: the opinions expressed and exchanged in such discussions are but the surface expression of deeply held beliefs rooted in an embodied ethos. This is true for O'Neill's former friends who accused her of hypocrisy, but it is also true for the pundits who spend their days defending their views and attacking others. What is at stake in these struggles is not simply an item on the agenda but the legitimacy and value of an embodied way of seeing. Although the terrain and modalities of explicitly political struggles 
are peculiar, the logic is essentially the same when we consider fashionistas or foodies showcasing their styles and tastes. Just as Bourdieu argued we need "to abolish the sacred frontier which makes legitimate culture a separate universe" (Bourdieu

1984, p. 6), we suggest that we should not separate out (and thereby consecrate) public debate as a distinct sphere of activity. By providing a unified framework for interpreting all expressions as status displays, Bourdieu's work serves as a warning against an opportunistic eclecticism that would view exchanges on Twitter as "political discussion" while considering the sharing of pictures on Instagram as an altogether different type of activity centering on cultural expression. This is where we follow Bourdieu: we consider all social media expressions as status displays, regardless of their specific content. Just as an unending series of appealing scenes and bodies in Instagram feeds does not indicate the absence of politics, heated exchanges on Twitter do not signal the absence of status politics.

This is not to say that social media can never perform a role in disrupting the status quo, but they only do so under specific circumstances. While accounts by Castells, Benkler and others suggest that transformations of the media landscape are structurally conducive for dissent, we make an opposite argument by arguing that the new media landscape (like the old media landscape) is structurally closed but contingently open. If activists want to use social media, they have to actively subvert its logic. Since dissent and criticism go against the grain, such subversion is a painstaking endeavor and challenging to sustain. Constant predation implies that social media users who speak out against the status quo are likely to face pushback, both in the short term, where they may face bullying, abuse and doxing, and in the long term, when digital traces of past activism come back to haunt them in job interviews. If activists are to use social media as a platform for expressing dissent, they have to actively carve out a space and create an environment where different norms and pressures apply. This requires sustained efforts to foster networks that are resilient against the pressures toward conformity. The formidable pressures for conformity are perhaps nowhere more visible than in the efforts of those seeking to subvert hegemonic norms by organizing on social media, such as feminists (Savolainen, Uitermark, and Boy 2019).

\section{A NEW MODEL}

Thinking about social media, what they are and what they do to us, is crucial at this juncture, when Silicon Valley's shiny promises are gradually being questioned. But there are old mental models that too often circumscribe how we think about the internet. This paper has sketched a way forward, proposing that we break with inherited mental models by adopting an alternate prism. Understanding online in- 
teraction in terms of the public sphere amounts to a category mistake. By applying the wrong category, we fail to see and take seriously many of the social and cultural processes actually taking place in digital spaces. If, instead, we apply the perspective we developed in here, these processes come into focus. More than that, without a more encompassing perspective like the one proposed above, the new needs that social media platforms fulfill remain entirely elusive. Why is it that people of all generations, and especially the young, keep using Facebook and other social media despite the widespread belief that doing so is unhealthy, unproductive and perhaps even detrimental to democracy? In this paper we suggested that there are specific structural pressures which do not determine people's actions, but nonetheless shape the formation of sensibilities and habits. These include the observance of decorum and etiquette, predation, and the alignment of one's character with one's outward persona. People attempt to criticize or escape these structural pressures, but only rarely succeed. There are examples of sustained and successful campaigns to change norms-think of Black Lives Matter or \#MeToo-but these should be understood as exceptions, not held up as paradigmatic.

Many of the processes we bring into focus here would either elude or irritate public sphere scholars.5 The focus on appearance and gossip appears as a mere distraction when we consider the social media as constitutive of a public sphere facilitating the exchange of information and opinions. But appearances and gossip appear in a different light when viewed through our lens: they are the lifeblood of status politics. The framework in this paper can direct our inquiries as we chart the relations formed through social media and probe social media users' desires and anxieties.

It may be easy to dismiss our framework for being applicable only to the case of Instagram, on which we have worked extensively (Boy and Uitermark 2016, 2017). And indeed, we developed the theorization of social media outlined in this paper based on data produced by a specific population in a particular place using a platform designed to facilitate visual communication. Considering these specificities, we readily concede that our case is hardly representative of other populations or platforms. But the same is true for other research that is based on data sourced from, say, Twitter or Facebook, that frequently informs research on political communications. One way to account for the differences between our observations of Instagram and others' observations of Twitter and Facebook, is to trace them back to the affordances of different platforms (Wellman et al. 2006; Dijck 2013). On this reading, the patterns of interconnection and pressures to conformity we observe are peculiar to Instagram and the specific functions the application offers its users.

\footnotetext{
${ }^{5}$ As Crystal Abidin was asked by an academic following a conference presentation, "Aren't these just young, rich women doing vain things online?" (see Abidin 2016).
} 
Although we readily agree that platforms have different affordances, we nevertheless feel this kind of argument is limited by its privileging of the technological underpinnings of social relations. Theorizing on affordances originated from the need to move beyond technological determinism and explicitly acknowledge that the same technological set-up allows for different kinds of social relations to emerge. And yet, technology remains the starting and end point of analysis - whatever happens, happens because technology affords it, leading researchers to scrutinize design decisions in minute detail.

We would suggest that the case of Instagram provides an alternative starting point for theorizing. Where researchers of political communication on Twitter or Facebook use their specific cases to theorize about debate and expressions of opinion, our case pushes us to consider them as status displays. Our theoretical perspective applied to a specific set of data enables us to identify processes and dimensions that may not have caught the attention of researchers working from a different theoretical perspective and studying different platforms.

\section{REFERENCES}

Abidin, Crystal. 2016. “'Aren't These Just Young, Rich Women Doing Vain Things Online?': Influencer Selfies as Subversive Frivolity." Social Media + Society 2 (2): 1-17. doi:10.1177/2056305116641342.

Adamic, Lada A., and Natalie Glance. 2005. "The political blogosphere and the 2004 U.S. election: Divided they blog." In Proceedings of the 3rd international workshop on Link discovery, 36-43. LinkKDD '05. ACM.

Arendt, Hannah. 1958. The Human Condition. Chicago: University of Chicago Press.

Benkler, Yochai. 2007. The Wealth of Networks: How Social Production Transforms Markets and Freedom. New Haven, Conn.: Yale University Press.

Berger, John. 1972. Ways of Seeing. London: Penguin.

Bourdieu, Pierre. 1984. Distinction: A Social Critique of the Judgement of Taste. Translated by Richard Nice. Cambridge, Mass.: Harvard University Press.

Bourdieu, Pierre, Luc Boltanski, Robert Castel, Jean-Claude Chamboredon, and Dominique Schnapper. 1990. Photography: A Middle-Brow Art. Translated by Shaun Whiteside. Stanford, Calif.: Stanford University Press.

Boy, John D., and Justus Uitermark. 2016. "How to Study the City on Instagram." PLOS ONE 11 (6): e0158161. doi:10.1371/journal.pone.0158161. 
Boy, John D., and Justus Uitermark. 2017. "Reassembling the city through Instagram." Transactions of the Institute of British Geographers 42 (2): 612-624. doi:10. 1111/tran.12185.

boyd, dana. 2006. "Super publics." March 22. http://www.zephoria.org/thoughts/archives/2006/03/ 22/super_publics.html.

boyd, danah. 2005. "Sociable Technology and Democracy." In Extreme Democracy, edited by Jon Lebkowsky and Mitch Ratcliffe. http://extremedemocracy.com/.

Castells, Manuel. 2009. Communication Power. New York: Oxford University Press.

Collins, Randall. 2004. Interaction Ritual Chains. Princeton, N. J.: Princeton University Press.

Dean, Jodi. 2002. Publicity's Secret: How Technoculture Capitalizes on Democracy. Ithaca, N. Y.: Cornell University Press.

2003. "Why the Net is not a Public Sphere." Constellations 10 (1): 95-112.

Diehl, Kristin, Gal Zauberman, and Alixandra Barasch. 2016. "How taking photos increases enjoyment of experiences." Journal of Personality and Social Psychology 111 (2): 119-140.

Dijck, José van. 2013. The Culture of Connectivity. New York: Oxford University Press.

Elias, Norbert. 1983. The Court Society. Translated by Edmund Jephcott. Oxford: Blackwell.

1991a. The Society of Individuals. Translated by Edmund Jephcott. Oxford: Blackwell.

1991b. The Symbol Theory. Edited by Richard Kilminster. London: Sage.

1994. The Civilizing Process: Sociogenetic and Psychogenetic Investigations. Translated by Edwin Jephcott. 2 vols. Oxford: Blackwell.

Foucault, Michel. 1979. An Introduction. Vol. 1 of The History of Sexuality. London: Allen Lane.

Giddens, Anthony. 1991. Modernity and Self-Identity: Self and Society in the Late Modern Age. Palo Alto, Calif.: Stanford University Press.

Goffman, Erving. 1959. The Presentation of Self in Everyday Life. London: Penguin. . 1979. Gender Advertisements. London: Macmillan. 
Goffman, Erving. 1986. Stigma: Notes on the Management of Spoiled Identity. New York: Simon \& Schuster.

Granovetter, Mark. 1973. "The Strength of Weak Ties." American Journal of Sociology 78 (6): 1360-1380. doi:10.1086/225469.

Habermas, Jürgen. 1991. The Structural Transformation of the Public Sphere: An Inquiry into a Category of Bourgeois Society. Translated by Thomas Burger. Cambridge, Mass.: MIT Press.

. 2006. "Ein avantgardistischer Spürsinn für Relevanzen: Was den Intellektuellen auszeichnet." Vienna, March 9. http://www.renner-institut.at/index.php?id=190.

Harari, Yuval Noah. 2015. Sapiens: A Brief History of Humankind. New York: HarperCollins.

Kaplan, Jonas T., Sarah I. Gimbel, and Sam Harris. 2016. "Neural correlates of maintaining one's political beliefs in the face of counterevidence." Nature Scientific Reports 6:39589.

Kolbert, Elizabeth. 2017. “Why Facts Don't Change Our Minds.” The New Yorker (February 27). https://www.newyorker.com/magazine/2017/02/27/why-facts-dont-change-our-minds.

Kotsko, Adam. 2017. "Jury Duty: How the internet became a tool for judgment rather than dialogue." Real Life (January 31). http://reallifemag.com/jury-duty/.

Lasch, Christopher. 1979. The Culture of Narcissism: American Life in an Age of Diminishing Expectations. New York: Norton.

Losse, Katherine. 2012. The Boy Kings: A Journey Into the Heart of the Social Network. New York: Free Press.

Marwick, Alice. 2014. Status Update: Celebrity, Publicity, and Branding in the Social Media Age. New Haven, Conn.: Yale University Press.

Milner, Jr., Murray. 2016. Freaks, Geeks, and Cool Kids: Teenagers in an Era of Consumerism, Standardized Tests and Social Media. 2nd ed. New York: Routledge.

Mirzoeff, Nicholas. 2015. How to See the World. London: Pelican.

Papacharissi, Zizi. 2002. "The virtual sphere: The internet as a public sphere." New Media \& Society 4 (1): 9-27.

Persson, Michael, Marije Vlaskamp, and Fokke Obbema. 2015. "China rates its own citizens-including online behaviour." Volkskrant (April 25). https://www.volkskrant.nl/ nieuws-achtergrond/china-rates-its-own-citizens-including-online-behaviour b4c0ae0e/. 
Piketty, Thomas. 2014. Capital in the Twenty-First Century. Cambridge, Mass.: Harvard University Press.

Reagle, Joseph. 2015. Reading the Comments: Likers, Haters, and the Manipulators at the Bottom of the Web. Cambridge, Mass.: MIT Press.

Ridgeway, Cecilia L. 1997. "Interaction and the Conservation of Gender Inequality: Considering Employment.” American Sociological Review 62 (2): 218-235.

RSPH. 2017. "\#StatusOfMind: Social media and young people's mental health and wellbeing." Royal Society for Public Health. https://www.rsph.org.uk/our-work/campaigns/ status-of-mind.html.

Savolainen, Laura, Justus Uitermark, and John D. Boy. 2019. "Filtering Feminisms." Manuscript submitted for publication.

Senft, Theresa M. 2013. "Hating Habermas: On Exhibitionism, Shame \& Life on the Actually Existing Internet." Either/And (November 10). http://eitherand.org/exhibitionis $\mathrm{m} /$ hating-habermas-exhibitionism-shame-life-actually-/.

Swaan, Abram de. 2001. Human Societies: An Introduction. Oxford: Blackwell.

Vaidhyanathan, Siva. 2018. Antisocial Media: How Facebook Disconnects Us and Undermines Democracy. New York: Oxford University Press.

Valkenburg, Patti, and Jessica Taylor Piotrowski. 2017. Plugged In: How Media Attract and Affect Youth. New Haven, Conn.: Yale University Press.

Varnelis, Kazys, ed. 2008. Networked Publics. Cambridge, Mass.: MIT Press.

Veblen, Thorstein. 1934. The Theory of the Leisure Class: An Economic Study of Institutions. New York: Modern Library.

Wellman, Barry, Anabel Quan-Haase, Jeffrey Boase, Wenhong Chen, Keith Hampton, Isabel Díaz, and Kakuko Miyata. 2006. "The Social Affordances of the Internet for Networked Individualism." Journal of Computer-Mediated Communication 8 (3): JCMC 834. doi:10.1111/j.1083-6101.2003.tbo0216.x.

Wouters, Cas. 2007. Informalization: Manners and Emotions Since 1890. London: Sage.

Zhang, Renwen. 2017. “The stress-buffering effect of self-disclosure on Facebook: An examination of stressful life events, social support, and mental health among college students." Computers in Human Behavior 75:527-537. 